\title{
GOVERNAR PELA AUTONOMIA: UNIVERSIDADE, INOVAÇÁO E CAPITALISMO COGNITIVO
}

\section{GOVERNING THROUGH AUTONOMY: UNIVERSITY, INNOVATION AND COGNITIV CAPITALISM}

\author{
Murilo Duarte Costa Corrêa \\ Doutorado em Direito pela Universidade de São Paulo. Professor Adjunto na \\ Universidade Estadual de Ponta Grossa. Paraná - PR - Brasil \\ mdc.correa@gmail.com \\ João Guilherme Pereira Chaves \\ Mestrando na Universidade Estadual de Ponta Grossa. Professor do cur- \\ so de Direito na Faculdade de Telêmaco Borba. Paraná - PR - Brasil \\ jgpchaves@hotmail.com \\ Diego Petyk de Sousa \\ Doutorando no Programa de Pós-Graduaçáo em Ciências Sociais Aplica- \\ das da Universidade Estadual de Ponta Grossa. Paraná - PR - Brasil \\ diegopetyk@uol.com.br
}

\begin{abstract}
Resumo: A segunda revoluçáo acadêmica, transcorrida entre os séculos XX e XXI, foi marcada pela integração universidades ao plano social da produção como atores do desenvolvimento socioeconômico regional, selando a interdependência entre as universidades e o setor produtivo. Este artigo objetiva descrever como um paradigma de governo neoliberal é internalizado pelas recentes transformaçóes da autonomia universitária. Para tanto, procede-se à revisão da literatura sobre a universidade empreendedora, discutindo sua economia política à luz do pós-estruturalismo de Michel Foucault e de teóricos do capitalismo cognitivo, como Maurizio Lazzarato e Franco Berardi. A pesquisa sugere que as transformaçôes da autonomia universitária acompanham a dinâmica do capitalismo global e do deslocamento de uma economia industrial a um capitalismo cognitivo ou imaterial. Nela, a autonomia universitária é tensionada como uma forma de governo ajustada ao modelo do capitalismo cognitivo e à abstraçáo financeira, tornando-se o elemento central de um paradigma de governo neoliberal emergente.
\end{abstract}

Palavras-chave: Autonomia. Capitalismo Cognitivo. Inovação. Neoliberalismo. Universidade.

AвstraCt:The second academic revolution occurred during the XX and XXI centuries, was characterized by the integration of the universities within developement and social goals, and constitutes the source of university and economy interdependence. This essay describes how the recent transformations of university autonomy embodied neoliberal patterns of government. Therefore, the paper reviews the literature on the entrepreneur university and discusses the related settings on economics and politics through Michel Foucault's post-structuralism and cognitive capitalist theorists, such as Maurizio 
Lazzarato and Franco Berardi. The research suggests that the transformations of the university autonomy and the new global and immaterial capitalist dynamics go along. In this context the university autonomy is converted into a form of government adjusted to cognitive capitalism and finance abstraction, becoming the key element of an emerging Neo-liberal paradigm of government.

KeYwords: Autonomy. Cognitiv Capitalism. Inovation. Neoliberalism. University.

\section{Introduçáo}

Entre o final do século XX e o início do século XXI, a segunda revolução acadêmica integrou as universidades ao plano social da produção como atores do desenvolvimento socioeconômico regional (ETZKOWITZ, 2008, p. 29). Isso instaurou uma relação de interdependência entre as universidades e o setor produtivo, deflagrando uma reorganizaçấo das universidades para gerar desenvolvimento e renda. Essa reestruturaçáo altera a lógica de funcionamento das universidades, afeta seus atores e transforma o setor produtivo privado no principal destinatário da inovação e parceiro preferencial de negócios, em uma economia predominantemente 'de conhecimento'.

Este artigo descreve como um paradigma de governo neoliberal, coalescente com a segunda revoluçáo acadêmica, acompanha as transformaçóes da autonomia universitária, com foco em uma das competências básicas da universidade pública: a atividade de pesquisa e inovação.

Uma das preocupaçôes centrais do sistema de inovação tecnológica repousa na relação entre tecnologia e desenvolvimento regional. No entanto, essa relação é moldada em termos político-econômicos, de modo que a universidade ocupa a posição de devedora da esfera social que, por sua vez, deveria encontrar na universidade uma força motriz para o seu desenvolvimento econômico-social. No entanto, em que consistem precisamente a renda, o desenvolvimento e o social que articula esse modelo de organização da pesquisa e da inovação? Eis o que parece ser voluntariamente obscurecido no léxico neoliberal da segunda revolução acadêmica e que constituem os elementos definidores de sua específica economia política e de subjetividade. Condicionadas pela economia política do neoliberalismo, a inovação tecnológica, as patentes, os royalties não atendem necessariamente aos interesses regionais, mas à pulsão acumuladora de setores econômi- 
cos já desenvolvidos, financeirizados e desterritorializados. Na medida em que a universidade, financiada com recursos públicos, torna-se por excelência "a devedora do social”, a relação de dívida - que, segundo Lazzarato (2017), é o novo rosto da governamentalidade neoliberal - é interiorizada não só pelas universidades em suas relaçóes com o Estado, a esfera social e o mercado produtivo, ou com o capital financeiro e especulativo, mas também é entronizada pelas pessoas que vivem e trabalham na universidade.

Isso gera um duplo efeito, institucional e de subjetividade. Sob a lógica neoliberal da dívida, a autonomia universitária será tensionada por um ideal de desenvolvimento social que, pouco a pouco, revela sua pulsão acumulativa e financeira, abstrata e desterritorializada. Isso implica não só que a universidade seja submetida à forma e à lógica de empresa, mas incorpore o papel de organizar os atores (alunos, professores, gestores, funcionários) segundo modos de subjetivação correspondentes, o que resume o papel das universidades em uma economia capitalista pós-fordista: a universidade funciona como empresa e replica sua lógica organizando uma rede de modos de subjetivação correlatos; não apenas busca saldar sua dívida (por definição, impagável) com a esfera do 'social', que a financia por meio de tributos, mas incorpora a lógica da dívida em suas estratégias de gestáo e a compartilha nos modos de subjetivação que circunscreve.

Gerar um ambiente universitário empreendedor passa a ser uma estratégia central de funcionamento para as universidades públicas, fomentando a pesquisa como instrumento da inovação e o empreendedorismo como modelo de ação de seus atores. O presente estudo parte da premissa de que as universidades são ambientes em que a produção tecnológica e humana, de subjetividades, se entrecruzam, propondo como grade de inteligibilidade as transformaçóes do capitalismo contemporâneo e da economia de conhecimento, que atribuem um papel central à ciência, à tecnologia e à inovação.

\section{As transformaçóes da autonomia universitária}

A autonomia das universidades que floresceram na Itália e na França a partir do século XI derivava da necessidade de organizar a produção e a difusão do conhecimento acumulado com independência em relação à 
Igreja e ao poder temporal (OLIVEIRA, 2007, p. 123). A pesquisa era desenvolvida em academias especializadas na medida em que a missão da universidade se restringia a difundir o conhecimento (RANIERI, 1994, p. 33). Dois grandes processos de transformação foram cruciais para ampliar sua competência original, levando as universidades a absorverem a atividade de pesquisa e a participação universitária no desenvolvimento sócio-econômico, o que Henry Etzkowitz (2008) chamou de 'revoluçóes acadêmicas'.

A primeira revoluçáo acadêmica teve origem na proposta de universidade apresentada por Humboldt e consistiu na integração das funçóes de pesquisa e ensino, postulando a independência da academia e a unidade entre o ensino e a pesquisa (GIMENEZ; BONACELLI, 2013), instaurando entre elas uma relação de enriquecimento recíproco. A unidade ensino-pesquisa maximizava o desenvolvimento e a difusão de conhecimento e mantinha a lógica da autonomia universitária, que remontava à sua origem tardo-medieval. Na medida em que a consolidação do Estado alemão só ocorreria em 1871, o modelo humboldtiano de universidade não se submetia a um controle governamental centralizado, mas a sistemas regionais de controle acadêmico, de modo que suas atividades estavam ligadas aos interesses locais, econômicos e sociais. (RANIERI, 1994, p. 57)

No começo do século XIX, outro modelo de universidade surgia: o napoleônico. A fim de preservar a estabilidade política do Estado, o modelo francês era marcado pela ausência de autonomia, pela gestão hierarquizada, por programas de ensino uniformes, pelo oferecimento de ensino profissionalizante e pela fragmentação da estrutura a partir de escolas superiores isoladas (GIMENEZ; BONACCELI, 2013). Esse modelo influenciou os dois primeiros séculos de experiência universitária brasileira. Da Colônia até a República, a direção exercida pelo Estado sobre as instituiçôes de educação superior buscava o controle social e a formação de elites (MATTOS, 1982, p. 04). A criação de cursos superiores por D. João VI, em 1808, inaugurou o modelo napoleônico de universidades no Brasil. Os cursos e academias destinavam-se a formar os funcionários da burocracia estatal e especialistas na produção de bens simbólicos (RANIERI, 1994, 63). Desse modo, até a República o sistema de educação superior 
brasileiro foi centralizado, focado na formação de elites e indiferente às necessidades regionais de mão-de-obra.

Ainda que a tradição brasileira tenha seguido em larga escala o modelo francês, o modelo humboldtiano inspirou as universidades que surgiram após o século XIX. Isso origina um padrão de funcionamento universitário híbrido, em que o ensino e a difusão do conhecimento são integrados à pesquisa, que tende à autonomia universitária, embora as universidades também sofram a influência do modelo napoleônico, estatal e de gestão hierarquizada e centralizada.

A segunda revolução acadêmica começa a ocorrer quando, na segunda metade do século XX (ALMEIDA; CRUZ, 2010), verifica-se o potencial da estrutura universitária para intervir na sociedade. A pesquisa e o ensino deixam de ser atividades de uma universidade endógena e autorreferente, tornando-se açóes potencialmente produtoras de intervençôes sociais. Ao lado das duas missóes originais - o ensino e a pesquisa -, a segunda revolução acadêmica amplia o escopo universitário: trata-se de transferir conhecimento para a sociedade, aproximar-se das demandas sociais e tornar-se um ator do desenvolvimento econômico e social. (ALMEIDA; CRUZ, 2010, p. 54)

A terceira missão servirá como um tensor das atividades da universidade, dando mais visibilidade ao ensino e à pesquisa, mais tarde integradas a atividades extensionistas, que também evoluem de cursos isolados e assessorias pontuais para práticas de contínua proximidade com a comunidade. Assim, a geração de conhecimento deve fomentar o desenvolvimento social, cultural e econômico (GIMENEZ; BONACELLI, 2013). Essas transformaçôes, ao mesmo tempo em que parecem desejáveis - pois aproximam a universidade da esfera social em que ela se insere, evitando que sua autonomia seja autorreferente -, colocam em xeque sua autonomia (em sentido humboldtiano), ao transcender o ensino e a pesquisa. Essa ampliação não apenas implica uma transformação da noção tradicional de autonomia, mas expõe as atividades universitárias às dinâmicas sociais e às influências do Estado e do setor produtivo, tanto para o financiamento de suas atividades quanto para o desenvolvimento de atividades de pesquisa e inovação. Eis o ponto em que sua autonomia se converte de uma marca histórica que garantia a independência dos saberes e da ciência contra toda pressão externa em um princípio de governo econômico-político. 


\section{O modelo empresarial}

A segunda revolução acadêmica não apenas levou as universidades a ampliarem suas funçôes, mas também desencadeou uma mudança estrutural mais profunda pela qual a racionalidade de empresa passa a integrar iniciativas de pesquisa, extensão e inovação. Como consequência, as universidades desenvolvem uma série de mecanismos administrativos e de gestão empresarial como a criação de escritórios de licenciamento de patentes e propriedade intelectual, incubadoras de inovação e instalação de parques tecnológicos.

Em The triple helix, Henry Etzkowitz (2008, p. 31) descreve a universidade empreendedora como um modelo inicialmente estadunidense, que hoje apresentaria tendências globais, no qual "cada professor tem a responsabilidade de financiar sua pesquisa.” Essa possibilidade estaria apoiada em uma universidade empreendedora: intimamente conectada com as demandas sociais e de desenvolvimento, ela superaria o modelo autorreferente da 'torre de marfim'; manter-se-ia independente de governos e mercados, nutrindo relaçóes positivas com ambos, e seria capaz de capitalizar o conhecimento ali produzido tornando-o passível de uso e transferência. Etzkowitz (2008, p. 41) resume esse modelo a cinco diretrizes: (1) a capitalização do conhecimento: essa é a base tanto para o desenvolvimento econômico e social quanto para definir um papel mais participativo da universidade. A capitalização do conhecimento impóe que os saberes universitários sejam criados e transmitidos tanto para o uso quanto para o avanço das disciplinas; (2) interdependência: deixando para trás o modelo da torre de marfim, a universidade interage tanto com os governos quanto com setores produtivos e da indústria; (3) a relativa independência da universidade em relação às esferas institucionais com que interage. As tensôes emergentes são mediadas pela (4) hibridização, que exige a criação de organizações híbridas capazes de realizar simultaneamente as tendências antagonistas. Por fim, (5) reflexividade: característica que exige uma contínua renovação e aperfeiçoamento da universidade e das esferas institucionais de governos e setor produtivo como resultado de suas interaçóes recíprocas.

O modelo das universidades norte-americanas nasceu conjunturalmente sob a lógica da segunda revolução acadêmica, ou da terceira missão. 
Nele, as universidades sempre foram dotadas de autonomia, náo existindo legislação nacional centralizadora ou subordinação das atividades universitárias a entes federativos. As universidades norte-americanas e sua produção científica e tecnológica sempre foram orientadas pragmaticamente para a economia, atingindo tanto as elites quanto as massas (RANIERI, 1994, p. 57). A predisposição histórica da universidade norte-americana em fazer parte do crescimento econômico teria justificado, talvez, o sucesso do sistema induzido pela decretação do Bayh-Dole Act ${ }^{1}$.

No contexto brasileiro, ferramentas da Lei de Inovação, como os Núcleos de Inovação Tecnológica e.g. ${ }^{2}$, parecem buscar transformar a universidade de uma estrutura voltada à difusão e produçáo de conhecimento, ou à formação de pessoal qualificado para o mercado de trabalho, em uma estrutura operacional voltada a uma funçáo empreendedora. Por um lado, isso implica seu envolvimento como um ator privilegiado do desenvolvimento econômico e social, mas, por outro, não permite uma clara determinação do significado e dos limites dessa nova função (GÖRANSSON et al., 2009, p. 84), o que resulta na falta de consenso teórico e na vagueza semântica dessa funçáo emergente nos documentos legais sobre políticas públicas voltadas à ciência e tecnologia.

As reformas legislativas relacionadas a Ciência, Tecnologia e Inovação realizadas nas últimas décadas no Brasil ${ }^{3}$ impuseram uma reorientação das próprias Instituiçôes de Ciência e Tecnologia (ICTs), que passaram a procurar maior captação de recursos com base em contratos de transferência de tecnologia e acordos de cooperação para desenvolvimento de produtos e processos. Em 2017, 24\% dos pedidos de depósito de patentes de invenção foram realizados por Instituiçôes de Ensino e Pesquisa, acima de empresas de médio e grande porte (INPI, 2018, p. 17); em 2016, 9 entre 10 maiores depositantes de patentes de invenção eram universidades públicas brasileiras (INPI, 2017, p. 21). De outro lado, as empresas privadas também se veem obrigadas a se aproximar das universidades e de órgãos públicos de inovação, ciência e tecnologia por razôes concorrenciais e de custeio produtivo.

Tudo isso converge para delinear os traços da terceira missão. As universidades contribuem para o processo de inovaçáo como fonte de conhecimento especializado para as áreas de tecnologia das empresas, mas também ao formar cientistas e engenheiros qualificados para a solução 
de problemas que emergem no processo inovador das firmas (RAPINI, 2007). Há, pois, um duplo movimento pelo qual a universidade internaliza a lógica empreendedora, produzindo externalidades positivas para o ambiente empresarial; a empresa, por sua vez, instrumentaliza o conhecimento universitário e tem sua atividade econômica modulada pela inovação tecnológica.

Nessa região de mútuo contágio, estabelece-se a possibilidade de que o professor e o pesquisador sejam os responsáveis diretos por financiar suas pesquisas por meio da aproximação do saber acadêmico ao setor produtivo, segundo uma lógica de capitalização do conhecimento, a partir de uma negociação supostamente pautada no interesse mútuo dos envolvidos e observando as regulaçóes governamentais promulgadas pelo Estado. Eis a tríplice hélice, um modelo que aposta no equilíbrio dinâmico e relacional do agenciamento entre universidade, setor produtivo e Estado, cujo empuxo retira as universidades da endogenia de sua torre de marfim, equilibrando a pulsão acadêmica dos pesquisadores com o utilitarismo pragmático do setor produtivo e a intervenção reguladora de órgãos govenamentais.

Essa lógica parece incorporada à Lei Federal n. 10.973/2004 (Lei de Inovação), que se baseia na "promoção da cooperação e interaçáo entre os entes públicos, entre os setores público e privado e entre empresas", assim como na "utilização do poder de compra do Estado para o fomento à inovação", e no "fortalecimento das capacidades operacional, científica, tecnológica e administrativa das ICT's" (BRASIL, 2004). Dessa maneira, a lei justifica a necessidade de maior interação empresa-universidade com a disposição do Estado em fomentar a inovação por meio de regulações e do exercício de seu poder de compra.

A obra de Etzkowitz (2008) aponta para a necessidade de reestruturação da universidade, incentivando a hibridação entre a racionalidade empreendedora e a lógica acadêmica. Isso atribuiria à universidade um papel mais ativo na criação de novos conceitos de negócio, favoreceria redes de colaboração com grupos externos, tornaria possível o financiamento da universidade com base em direitos sobre patentes, propriedade intelectual e royalties oriundos do licenciamento junto a empresas. Seu mais recente conjunto de competências configura o modelo da universidade empreendedora, cuja chave é a capitalização do conhecimento, a transformação do pesquisador em responsável pelo financiamento de suas próprias pesqui- 
sas, a abertura da universidade à lógica do mercado e a participação do Estado no fomento e na regulação.

No entanto, no léxico aparentemente imparcial com que se descreve o fim do isolamento autorreferente das universidades, a sua transformação em agente de desenvolvimento social e econômico, a sua hibridação com a racionalidade empreendedora, o seu equilíbrio dinâmico com o setor produtivo, que passa a financiar a pesquisa e a inovação, e com o Estado, que passa a fomentá-la e a regulá-la, deixa intocado um problema central. A própria forma discursiva, voluntariamente evolucionista (ETZKOWITZ, 2008) ou didaticamente paradigmática (GIMENEZ; BONACELLI, 2013), como a sucessão das revoluçóes e missóes das universidades é apresentada na literatura tende a neutralizar a opção econômico-política pressuposta pelo modelo da universidade empreendedora. Obscurece, também, a posição central que as universidades passam a ocupar no contexto de uma economia global do conhecimento, assim como não se dedicam às consequências subjetivas da adoção desse modelo.

\section{A universidade na era capitalismo cognitivo}

As transformações que a universidade e sua autonomia atravessaram nas últimas décadas acompanham as mutaçôes do próprio capitalismo. Ao propor um modelo empreendedor, regulado e em equilíbrio dinâmico entre a universidade e as esferas da produção e do Estado, a obra de Etzkowitz (2008) é exemplar para compreender como as novas dinâmicas de capitalismo global e financeiro, pós-fordista e pós-industrial, investem o corpus da universidade no contexto de uma nova divisão internacional do trabalho cognitivo.

Não é casual que Etzkowitz (2008) afirme desde as primeiras linhas de The triple helix que "A interação entre universidade, setor produtivo e governo é a chave para a inovação e o crescimento em uma economia de conhecimento" (ETZKOWITZ, 2008, p. 01). É que a universidade está para a sociedade do conhecimento como a indústria e os governos estiveram para a sociedade industrial. Seu modelo de tríplice hélice introduz uma lógica empreendedora como meta acadêmica e conteúdo de uma base curricular formativa comum, requerendo a intervenção do Estado como 
investidor de capital de risco em pesquisa e inovação e como ente regular das relaçóes entre universidade e mercado. Isso implica adotar uma racionalidade governamental de tipo neoliberal, em que a intervenção do Estado não apenas é desejável e necessária (LAZZARATO, 2011, p. 18; BERARDI, 2017, p. 148), mas deve ser situada em um "limiar ótimo", evitando tanto a completa desregulação - que arrisca perder de vista as metas sociais do empreendimento de inovação - quanto a intervenção excessiva, limitadora da livre iniciativa (ETZKOWITZ, 2008, p. 74).

Toda atividade de inovação na universidade transforma-se capital de risco desigualmente partilhado entre: (1) capital humano: professores e pesquisadores, social e produtivamente situados, com perfil empreendedor, responsáveis pela matéria da inovação e por organizar seu desenvolvimento em estruturas que se encontram a meio-caminho entre a universidade e a empresa como incubadoras, startups ou firmas, com potencialidade para gerar receitas futuras, baseadas em rendas de licenças e royalties derivadas das inovaçôes; (2) capital financeiro: entes privados que investem financeiramente no desenvolvimento de dada inovação, podendo obter futuras licenças de uso e comercialização; (3) órgãos estatais: funcionam tanto como parceiros de investimentos de risco para pesquisas que não logrem captar recursos no mercado quanto como mediadores do equilíbrio das relaçôes entre universidade e mercado.

Trata-se de constituir não apenas organizaçóes e agências, ou instituições híbridas destinadas a favorecer a interação entre esses três atores dos processos de inovação, mas de materializar um espaço aberto à sua integração, como a criação de uma tecnópolis: um espaço de interação em rede, inter ou transdisciplinar, que resultaria da densificação da atividade de centros de pesquisa, escritórios de transferência de tecnologia, incubadoras, firmas de inovação, startups e parques científicos, e que seria uma espécie de polo sintetizador de iniciativas de inovação, colaborando para formar uma "fonte auto-sustentável e regenerativa de desenvolvimento econômico e social [...]" (ETZKOWITZ, 2008, p. 90). A tecnópolis de Etzkowitz talvez esteja para a sociedade baseada na economia do conhecimento como o panopticon de Bentham estava para as sociedades industriais. A tecnópolis constitiu um espaço ideal em que dispositivos empresariais de captura e controle subsumem um amplo tecido de relaçóes biopolíticas que se encontram na base da pesquisa e da inovação. 
Portanto, é preciso levar a sério a capitalização do conhecimento nas universidades. Ela dá a ver náo só que o conhecimento passa a ser objeto de um investimento do capital, mas que ele se torna uma nova divisa de valor em um capitalismo de novo tipo, que envolve um outro modelo de exploração do trabalho e da subjetividade, organizado em escala mundial. Esse diagnóstico se encontra no coração da proposta de Etzkowitz (2008, p. 04) ao propor o modelo de tríplice hélice como solução de produção de valor frente à desterritorialização em escala global que caracteriza as fases mais recentes da nova divisão internacional do trabalho ${ }^{4}$. O modelo da tríplice hélice e da universidade empreendedora pressupóe toda uma economia política e de governo que transforma a atividade de pesquisa, o funcionamento das universidades e as formas de vida e subjetivação na universidade.

Etzkowtiz, no entanto, compreende muito bem a natureza desse modelo econômico-político. Não só por advogar o caráter expansivo do empreendedorismo (ETZKOWITZ, 2008, p. 02), ou a meta financista de conversão das iniciativas de empresas universitárias inovadoras (op. cit., p. 05). A chave está em perceber o que faz da universidade o centro de gravidade da estratégia da tríplice hélice e da universidade empreendedora. O próprio Etzkowitz $(2008$, p. 01) dirá que a vantagem competitiva que as universidades têm em relação a outras instituiçôes de pesquisa e desenvolvimento são seus estudantes. Submetidos a uma dinâmica de contínuo ingresso e graduação, eles são o capital humano potencialmente gerador de novas ideias, em contraste com a dinâmica ossificada de setores de pesquisa de empresas e governos, marcados pela escassez de fluxo de capital humano.

Essa rápida reconstrução do pano de fundo do modelo da tríplice hélice permite descrever as premissas econômico-políticas de sua "sociedade baseada em conhecimento" como resultado do cruzamento entre o biocapitalismo, o capitalismo cognitivo e as sociedades de controle, agenciadas segundo uma forma de governo neoliberal em que a autonomia, como pressuposto para a liberdade de empreender, desempenha um papel central. Antonio Negri (2015, p. 57-58) definiu o biocapitalismo como "um capitalismo que, para sua valorização [...], investiu a totalidade da sociedade [...] isto é, o conjunto da vida humana individual e social que é posta, enquanto tal, a trabalhar". O investimento da totalidade da vida hu- 
mana e social pelo capital é o ponto de chegada de uma série de transformaçôes sócio-técnicas e econômicas que redefinem o capitalismo pós-fordista como uma regulação que já não se opera entre a fábrica e a sociedade, mas "diretamente no nível social [...] na relação entre a organização social do desenvolvimento, da economia, das formas de exploraçáo do trabalho em geral e da vida [...]" (op.cit., p. 58).

A condição para que a universidade seja convocada a desempenhar a terceira missão, o papel de ator ou catalisador de processos de desenvolvimento organizado do social, não é uma economia do conhecimento em sentido estrito, mas um investimento da vida social pela máquina capitalista mais vasto e profundo. As transformaçóes do capitalismo contemporâneo, que passa a investir a totalidade da vida e das relaçóes sociais, convertendo-as em ponto de origem de processos financeiros cada vez mais abstratos de valorização econômica (BERARDI, 2012, p. 104), articulam-se às transformaçôes sociais que correspondem à passagem das sociedades industriais, erigidas sob o modelo produtivo da fábrica e do trabalho material, repetitivo e assalariado, ao que Gilles Deleuze (2008, p. 219-226) denominou "sociedades de controle", modeladas pela lógica pervasiva da empresa e das finanças. Três linhas de objetividade definem, portanto, o pano de fundo econômico-político da economia de conhecimento e da sociedade que lhe corresponde: (1) um biocapitalismo que investe a totalidade da vida humana e social, subsumindo toda atividade humana à valorização capitalista; (2) um processo de abstração dos processos de valorização capitalista da atividade humana, inseridas pelas lógicas da empresa e da financeirização, cuja marca é destruir os referenciais materiais que, nas sociedades industriais, caracterizavam o trabalho, a produção e serviam de esteio ao padrão capitalista de valor; (3) uma estrutura social que se caracteriza pelo fim do confinamento disciplinar aos espaços fechados (fábricas, escolas, hospitais, prisões etc.) e pela dispersão de seus dispositivos de controle em um meio aberto, virtualmente ilimitado e pela introdução "da 'empresa' em todos os níveis de escolaridade" (DELEUZE, 2008, p. 225).

Para compreender como essas três linhas de objetividade se agenciam e transformam a autonomia em uma forma de governamentalidade ajustada ao modelo de capitalismo cognitivo ou imaterial, propomos reler o modelo de universidade empreendedora a partir não mais do modelo da 
tríplice hélice, mas do tríplice dispositivo de poder que a sua economia/ sociedade do conhecimento supóe.

\section{O tríplice dispositivo governamental: autonomia- competiçáo-dívida}

O modelo da universidade empreendedora se baseia na exploração biocapitalista da atividade cognitiva e do capital humano, dependentes de uma reorganizaçáo do modelo produtivo. A atividade de pesquisa, voltada ao desenvolvimento de tecnologia e inovação, ainda que possa resultar em produtos tangíveis, comercializáveis, ou em técnicas produtivas, consiste em uma atividade intrinsecamente intelectual ou imaterial ${ }^{5}$. A pesquisa constitui uma atividade cognitiva que envolve e mobiliza todas as dimensóes da subjetividade dos trabalhadores intelectuais que a realizam (LAZZARATO; NEGRI, 2001, p. 25), sob uma forma de organização baseada na autonomia, governada a partir da indistinção entre o social e o econômico. O que caracteriza o capitalismo cognitivo, ou imaterial, é o fato de elementos da subjetividade como as capacidades relacionais, afetivas, criativas, linguísticas, simbólicas, disruptivas etc. dos trabalhadores intelectuais terem passado ao cerne dos processos de valorização capitalista nas últimas décadas do século XX (HARDT; NEGRI, 2005, p. 149). Uma economia de conhecimento lastreada na pesquisa e voltada à inovação consiste em um recorte parcial desse pano de fundo mais amplo das transformaçóes do capitalismo mundial, que tornaram um trabalho biopolítico, social e tendencialmente imaterial em termos qualitativos sua fonte privilegiada de valor (HARDT; NEGRI, 2005, p. 150-153).

Privatizar a universidade, no léxico esgotado das esquerdas, já não é entregar a universidade pública à gestão de pessoas jurídicas privadas, animadas pelo lucro, mas criar um conjunto de condiçôes políticas, econômicas, sociais e de subjetivação capazes de produzir uma transição de racionalidade como um processo sutil, difuso, global (ETZKOWITZ, 2008, p. 137) e progressivamente interiorizado pela universidade, como se tivesse nascido espontaneamente de seus 'novos desafios'. Trata-se de uma reconfiguração à qual o próprio Estado é chamado a participar, nos termos de uma intervenção ótima de fomento-regulação. 
A autonomia, a competição e a dívida constituem os três dispositivos que serão associados à universidade para prover as condiçóes para que o trabalho imaterial da pesquisa e da inovação possa ser explorado na matriz pós-industrial do capitalismo cognitivo e biopolítico. Cada um desses dispositivos funciona articuladamente com os demais, visando a governar transversalmente as dinâmicas do trabalho cognitivo e os modos de subjetivação dos trabalhadores imateriais da pesquisa.

\subsection{Autonomia}

A autonomia universitária, que originalmente era o signo de um distanciamento crítico entre a universidade e os sistemas espiritual (Igreja) e temporal (Estado) de veridicção, constitui o elemento central desse novo paradigma de governo. A autonomia designa não só a condição de organização necessária à exploração do trabalho imaterial (cognitivo, inventivo, disruptivo); ela também dá consistência à alternativa neoliberal, comumente vista como a única saída crise do financiamento público universitário. A autonomia é, a um só tempo, a matriz biopolítica do trabalho imaterial vivo e em movimento, cuja produção contínua será vampirizada, mas também a forma de organização historicamente consolidada que identifica a produção de capital cognitivo nas universidades. $\mathrm{O}$ que falta, para seguir ainda uma expressão de Etzkowitz (2008, p. 95), é "capitalizar o conhecimento."

Isso significa reorientar mediante outras tecnologias econômicas e de poder pervasivas o sentido de autonomia. A segunda revoluçáo acadêmica e a assunção da terceira missão das universidades não são guiadas por objetivos econômico-sociais por outra razão. A questão não é abstrata: “deve-se ou não tornar a universidade socialmente referenciada?" - falsoproblema que exige uma resposta tão positiva quanto vaga -, mas que conteúdo tem o social que passará a referenciar sua atividade? Ou seja, o que é, quem é, do que é feito o social para quem o cognitariado ${ }^{6}$ universitário passa a trabalhar?

Michel Foucault (2008, p. 365) e Maurizio Lazzarato (2011, p. 15-16) propuseram que a chave do liberalismo e das formas de governo neoliberais esteve, desde o início, em governar o social, de forma que o 
social se torna um modo de governo. A sociedade não seria uma massa amorfa de indivíduos, uma matéria preexistente, mas o correlato de técnicas que governo que têm por objetivo governar condutas por meio de um convênio entre o mercado e o Estado - daí porque haverá um nível ótimo de intervenção do Estado. Trata-se de intervir para criar um terreno social pontilhado de desigualdades, um estado compartilhado de "igual desigualdade" (LAZZARATO, 2011, p. 22), que lance as condiçóes materiais mínimas para produzir artificialmente um mercado concorrencial (cf. item 4.2, à frente).

A autonomia universitária desempenha, aqui, um papel estratégico. Ela é a condição organizativa historicamente pré-constituída do trabalho universitário, mas também o dispositivo que permitirá que o social, como paradigma de governo, passe a dirigir sua racionalidade. Ao descrever o liberalismo como arte de governar, Foucault (2008, p. 86-89) notava que a liberdade não só não era um universal progressivamente realizado no curso histórico, como se encontrava indexada, interiorizada, subministrada e governada pelo próprio modelo liberal de governo. O paradigma de governo liberal só pode existir sob a condiçáo de secretar e consumir um certo número de liberdades. A liberdade é tanto uma produção governamental quanto uma condição para seu funcionamento.

No capitalismo cognitivo, sob o regime social da desigualdade concorrencial (cf. item 4.2) e da dívida (cf. item 4.3) como elemento motriz da captação privada de financiamento, no nível institucional, e de exploração de trabalho, no nível individual, a autonomia universitária é a liberdade essencial que permite articular a auto-organização de um cognitariado criativo à maquina governamental neoliberal. A autonomia universitária passa a ser a excusa pelas quais as universidades já não podem depender exclusivamente de financiamentos públicos, ao mesmo tempo em que representa a condição para que as pesquisas se tornem ativos virtuais, dependentes de um mercado privado de investimentos.

\subsection{Competição}

É a um 'social' ativamente pontilhado por desigualdades, que criam artificialmente uma condição concorrencial generalizada, que a universi- 
dade, a pesquisa e a inovaçáo passam a estar indexadas. E o social, como quisera Lazzarato (2011, p. 16), longe de ser uma substância, é um modo de governo que, sob as artes liberal e neoliberal de governar, tende à criação de condiçóes ótimas para o desenvolvimento de um mercado concorrencial e internaliza toda liberdade e autonomia como condiçóes de sua racionalidade e funcionamento. No entanto, embora se insista no caráter regional do desenvolvimento econômico e social gerado pelo modelo empreendedor de universidade, a economia política que esse modelo globalmente difundido pressupóe é transnacional (ETZKOWITZ, 2008, p. 29) e tendencialmente orientada a um capitalismo de tipo financeiro.

Isso corresponde a um duplo regime de sujeição ao capitalismo cognitivo integrado em nível mundial. Por um lado, as universidades competem entre si, no mercado global, pela liderança em diversas áreas e disciplinas, especialmente nas de tecnologia e inovação - áreas tão sensíveis ao capitalismo imaterial; proliferam as estruturas de avaliação e rankeamento; estabelecem programas de cooperação internacional em pesquisa e desenvolvimento; são avaliadas por sua capacidade de gerar patentes e licenciar tecnologia etc. Por outro, a própria atividade de pesquisa é desterritorializada em consequência dos fluxos abstratos de 
tiva, gestado no interior de instituiçóes de capitalização de conhecimento em que as universidades se convertem.

\subsection{Dívida}

Ainda que a atividade de pesquisa do cognitariado consista na fonte de inovação cuja produtividade geral passa a ser explorada, é preciso moldar subjetividades dóceis a essa finalidade. Isso se dá tanto pela via disciplinar quanto pelo imperativo de a 'educação empreendedora' penetrar todos os níveis de formação educacional (ETZWOKITZ, 2008, p. 03), como por meio de dispositivos de poder e de subjetivação mais pervasivos.

Seus efeitos originam uma nova economia psíquica que assume a forma da dívida (LAZZARATO, 2017, p. 60; BERARDI, 2017, p. 156). A economia da culpa que a forma da dívida supóe não só instaura novas distribuiçôes de desigualdades compartilhadas, instauradoras das condiçôes concorrenciais que definem o social como paradigma de governo; ela impóe tecnologias existenciais responsáveis por fabricar os modos de subjetivação correspondentes à articulação entre autonomia e competição.

O trabalho imaterial se organiza autonomamente; dirige seus próprios processos, mobiliza seus meios, autoproduz suas relaçóes de cooperação, organiza e retroalimenta suas capacidades competitivas, gera as semioses que o particularizam (LAZZARATO e NEGRI, 2001, p. 94). E são precisamente esses traços positivos que o capitalismo explora em um mercado de trabalho cognitivo unificado em nível global. A condição comum a que esses trabalhadores cognitivos se subordinam consiste na mobilização de seu capital humano - formado em escolas e universidades, mas também pela experiência de vida, relaçóes sociais, afetivas, capacidades emocionais e cognitivas etc. - em vastas redes internacionais de competição, geralmente a título precário (como os grants de pesquisa e desenvolvimento com duração limitada, sem garantias empregatícias associadas).

Atrelada a essa nova divisão internacional do trabalho cognitivo, a dívida desempenha aqui, tanto no nível individual quanto no institucional, o elemento de chantagem (BERARDI, 2017, p. 152) que funda uma economia psíquica adaptada à universidade empreendedora. Por meio dela, o homo academicus (BOURDIEU, 1984) é agora subjetivado como 
homo xeconomicus (FOUCAULT, 2004), como empresário de si mesmo (DARDOT; LAVAL, 2016). Essa subjetividade é ativamente fabricada. Em largos traços, ela corresponde ao pesquisador-empresa, isto é, o pesquisador cuja atividade é continuamente fabricada, controlada, moldada e dirigida pela cultura da empresa. Submerso na competição mundial, o pesquisador-empresa não se move apenas no terreno da produção econômica, da aquisição de capital humano e simbólico, mas instaura uma relação consigo, de autoprodução subjetiva, integralmente orientada pela racionalidade do homo aconomicus. Nessa condição, a empresa torna-se o modelo da relação consigo mesmo (DARDOT; LAVAL, 2016, p. 328), a racionalidade geral constitutiva de uma forma de vida específica, uma tecnologia existencial. O pesquisador-empresa é alguém que deve à universidade (da qual recebe um salário), ao Estado (que fomenta suas atividades), ao mercado (que financia suas pesquisas potencial ou efetivamente), ao social (que financia a universidade, ou que dirige os objetivos de sua pesquisa) e a si mesmo, sob a forma do reinvestimento incansável em seu capital humano e da excitação narcisista do risco (BERARDI, 2005, p. 58).

Esses processos governamentais, de constituição social e de subjetivação, estão articulados entre si. Michel Foucault não só afirmou que a sociedade civil é "um conceito de tecnologia governamental cuja medida racional deve indexar-se juridicamente a uma economia”, mas que o sujeito que lhe corresponde, o homo æeconomicus, integra "o conjunto da tecnologia da governamentalidade liberal” (FOUCAULT, 2008, p. 402-403).

A dívida opera em um duplo horizonte, institucional e subjetivo, no qual se movem universidades e pesquisadores. É precisamente a articulação do dispositivo de dívida nesses dois domínios que condiciona a extração de trabalho cognitivo útil (inovação) e sua exploração nos termos da semiose competitiva da cultura de empresa. A destruição dos mutualismos característicos do Estado de Bem-Estar Social com as investidas neoliberais que ocorrem a partir da década de 1970 impóem a substituição de direitos sociais (baseados na solidariedade) pelo acesso ao crédito (e ao endividamento). E essa lógica atravessa tanto indivíduos quanto instituiçóes.

Tensionada pelos objetivos do 'social' e do desenvolvimento econômico regional - que, como vimos, não passam de eufemizaçóes para a subordinação do cognitariado universitário ao mercado internacional da financeirização do conhecimento -, a universidade pública nem serve aos 
mais vulneráveis, com suas licenças de uso e patentes de inovação, nem fica imune de uma culpa institucional difusa por ser financiada por impostos. A posição permanente de dívida da universidade pública em face do social, que a financia por meio do orçamento público, é o 'fantasma de grupo' que expóe o cognitariado e a própria universidade, no flanco de sua autonomia, aos múltiplos sistemas de captura do capitalismo cognitivo e financeiro.

Do ponto de vista subjetivo, a potência da dívida como dispositivo está no fato de que seu poder de controle não é exterior, mas habita a subjetividade do próprio devedor, hipoteca seu tempo futuro e extrai trabalho útil, docilidade, colaboração sistêmica (LAZZARATO, 2017, p. 67). A relação de crédito e débito implica um modo de subjetivação marcado pela interiorizaçáo das relaçóes de poder, desprovido de qualquer solidariedade; promove no mais fino grão da subjetividade (a vergonha e a culpa) uma nova etapa da ascese capitalista, que consiste na sujeição do comportamento individual e institucional à racionalidade de empresa.

\section{Consideraçóes Finais}

As transformações da autonomia universitária acompanham a lógica das transformaçóes do capitalismo global e do deslocamento de uma economia industrial a um capitalismo cognitivo ou imaterial. A segunda revolução acadêmica e a assunção da terceira missão, à custa de dissociar a universidade do modelo endógeno e autorreferente da torre de marfim promovendo uma universidade social e economicamente referenciada, podem ser interpretadas como reflexos das transformaçóes tardias da economia capitalista.

No contexto do modelo brasileiro de universidade, pesquisa e inovação, o paradigma empresarial de universidade surge como a desejável solução aos novos desafios institucionais, ligados, de um lado, à escassez de recursos públicos para o financiamento das atividades-fim de ensino, pesquisa e extensão universitárias; de outro, ao novo desafio de desertar a arrogante torre de marfim para intervir na sociedade, na economia e no desenvolvimento regional. $\mathrm{O}$ modelo empreendedor de universidade representaria, ainda, uma vantagem: a de capturar a oportunidade do 
crescente investimento privado e público na economia da inovação, que encontra nas universidades públicas um manancial de capital humano flutuante, relativamente precarizado, potencialmente gerador de novos fluxo de ideias passíveis de uso, aplicação e transmissão.

A adoção desse modelo, que encontra na tríplice hélice de Etzkowitz seu mais completo acabamento conceitual, porém, apresenta a opção econômico-política que ele pressupóe como uma realidade neutral que tanto obscurece as condições materiais que alocam a universidade no centro de uma economia global do conhecimento quanto não desenvolve suas consequências subjetivas. Nesse modelo, a autonomia universitária é tensionada como uma forma de governo ajustada ao capitalismo cognitivo, imaterial e à abstração financeira, tornando-se o elemento central de um paradigma de governo neoliberal emergente. Isso porque a autonomia universitária é a condição organizativa e historicamente préconstituída do trabalho cognitivo universitário, a liberdade essencial que permite articular a auto-organizaçáo de um cognitariado criativo à maquina governamental neoliberal.

A submissão a essa lógica transforma as pesquisas em ativos virtuais, dependentes de um mercado privado de investimentos, e as universidades em instituiçôes de capitalização de conhecimento, mobilizando para tanto um tríplice dispositivo: a autonomia, como liberdade internalizada, organizada, dirigida e tensionada pela lógica empresarial e de mercado; a competição, como condiçáo social ativamente predisposta pela intervençáo ótima do Estado, que organiza uma sociedade artificialmente desigual, funcionalmente concorrencial e subjetivamente governável pela cultura de empresa; e a dívida, organizada no plano institucional e no individual, como dispositivo de chantagem financeira e de subjetivação do pesquisador-empresa, extrator de trabalho intelectual e de tempo futuro a serem subsumidos à governamentalidade financeira de um mercado cognitivo integrado em nível global.

\section{Notas}

1 O Bayh-Dole Act foi uma reforma legislativa que ocorreu nos Estados Unidos da América na década de 1980 e focava na aproximação entre universidade e setor produtivo. Visava a fomentar uma dinâmica em que a universidade gera tecnologia, por meio do conhecimento e da pesquisa, 
e a licencia para o setor produtivo, obtendo lucros de royalties por propriedade intelectual para a universidade. Esse sistema foi reproduzido no mundo inteiro, inclusive pelas reformas legislativas brasileiras como a Lei Federal de Inovaçáo e o Marco da Ciência, Tecnologia e Inovação. Em linhas gerais, a universidade pública, que hoje constitui a maior fonte brasileira de pesquisa, conforme o relatório Research in Brazil (CLARYVATE ANALYTICS, p. 44, 2018), licencia sua tecnologia ao setor produtivo.

2 O artigo $2^{\circ}$, inciso VI, da Lei de Inovação (Lei Federal n. 10.973/2004), define os Núcleos de Inovação Tecnológica (NIT) como estruturas instituídas por uma ou mais Instituiçôes de Ciência e Tecnologia (ICT), com ou sem personalidade jurídica própria, que tenham por finalidade a gestâo de política institucional de inovação.

3 O que inclui desde a Lei Federal no 10.973 de 2004 (Lei da Inovação), a proliferação de leis de inovação em âmbito estadual e, mais recentemente, a Emenda Constitucional no 85 de 2015, que confere maior destaque à a inovação tecnológica na Constituiçáo da República, e o Marco da Ciência, Tecnologia e Inovação, Lei Federal no 13.243 de 2016.

4 "Na medida em que os empregos são terceirizados e cada vez mais realocados em outros países com pessoas altamente capacitadas e a salários mais baixos, qual será o futuro motor do crescimento econômico, especialmente o de "alta tecnologia?", pergunta-se Etzkowitz (2008, p. 04).

5 Henry Etzkowitz (2008, p. 05) reconhece explicitamente: “[...] uma sociedade baseada no conhecimento funciona de acordo com um conjunto diferente de dinâmica, face a uma sociedade industrial, focada em fabricar bens tangíveis. Economias baseadas em conhecimento são mais estritamente ligadas a fontes de novos conhecimentos; elas também estão sujeitas a transformaçóes contínuas ao invés de estarem enraizadas em arranjos estáveis." É curioso notar, ainda, como nesse excerto, a exemplo do que ocorre em muitos outros, Etzkowitz utiliza as expressóes "knowledge-based society" e "knowledge-based economies" como sinônimas, passando livremente de uma a outra sem qualquer mediaçấo conceitual.

6 A partir de uma atualização do conceito marxiano de General Intellect, Franco Berardi (2005, p. 72) definiu o cognitariado como classe, isto é, como "o fluxo de trabalho semiótico socialmente difuso e fragmentado, considerado do ponto de vista de sua corporeidade social." Ainda que sua definição esteja originalmente relacionada à economia digital do Vale do Silício e sua crise, o conceito parece poder se estendido a um conjunto mais amplo de trabalhadores cognitivos, e é com esse ânimo que o empregamos.

\section{Referências}

ALMEIDA, Daniella Rocha de; CRUZ, Angela Duran Aparecida da. O Brasil e a segunda revolução acadêmica. Interface da Educ., v. 1, n. 1, pp. 53-65, 2010. Disponível em: <https://periodicosonline.uems.br/index.php/interfaces/article/view/648/612>. Acesso em: 01 out. 2018.

BERARDI, Franco 'Bifo'. A fábrica da infelicidade: trabalho cognitivo e crise da new economy. Tradução de Orlando dos Reis. Rio de Janeiro: DP\&A, 2005.

. Futurability: the age of impotence and the horizon of possibility. London:

Verso Books, 2017.

The uprising: on poetry and finance. South Pasadena: Semiotext(e), 2012. 
BRASIL. Lei Federal n. 10.973, de 02 de dezembro de 2004. Dispóe sobre incentivos à inovação e à pesquisa científica e tecnológica no ambiente produtivo e dá outras providências, Brasília, DF. Disponível em: <http://www.planalto.gov.br/ccivil_03/_ Ato2004-2006/2004/Lei/L10.973.htm>. Acesso em: 01 out. 2018.

CLARIVATE ANALYTICS. Research in Brazil: a report for CAPES by Clarivate Analytics. 2018. Disponível em: <http://www.capes.gov.br/images/stories/download/ diversos/17012018-CAPES-InCitesReport-Final.pdf>. Acesso em: 01 out. 2018.

DARDOT, Pierre; LAVAL, Christian. A nova razão do mundo: ensaio sobre a sociedade neoliberal. Tradução de Mariana Echalar. São Paulo: Boitempo, 2016.

DELEUZE, Gilles. Conversações. Tradução de Peter Pál Pelbart. São Paulo: Editora 34, 2008.

ETZKOWITZ, Henry. The triple helix: university, industry, government. Innovation in action. New York: Routledge, 2008.

FOUCAULT, Michel. Nascimento da biopolítica. Tradução de Eduardo Brandão. São Paulo: Martins Fontes, 2008.

GIMENEZ, A. M. N.; BONACELLI, M. B. M. Repensando o papel da universidade no século XXI: demandas e desafios. Rev. Tecnologia e Sociedade, v. 9, n. 18, sp., 2013. Disponível em: <https://periodicos.utfpr.edu.br/rts/article/view/2623>. Acesso em: 01 out. 2018.

GÖRANSSON, B.; MAHARAJH, R.; SCHMOCH, U. Introduction: New challenges for universities beyond education and research. Science and Public Policy, v. 36, n. 2, p.83-84, 2009. Disponível em: <https://academic.oup.com/spp/articleabstract/36/2/83/1631727>. Acesso em: 01 out. 2018.

HARDT, Michael; NEGRI, Antonio. Multidão: guerra e democracia na era do Império. Tradução de Clóvis Marques. Rio de Janeiro: Record, 2005.

INSTITUTO NACIONAL DE PROPRIEDADE INTELECTUAL. Relatório de atividades 2017. Rio de Janeiro, 2018. Disponível em: <http://www.inpi. gov.br/sobre/estatisticas/arquivos/publicacoes/RA2017v_006a131A4vPT_ BRVisualizacaobitmap144dpi.pdf >. Acesso em: 05 out. 2018.

Indicadores de propriedade industrial: o uso do sistema de propriedade industrial no Brasil. Rio de Janeiro, 2017. Disponível em: <http://www.inpi.gov.br/ sobre/estatisticas/arquivos/indicadores_pi/indicadores-de-propriedade-industrial-2017 versao_portal.pdf >. Acesso em: 05.10.2018.

LAZZARATO, Maurizio. O governo das desigualdades: crítica da insegurança neoliberal. Tradução de Renato Abramovicz Santos. São Carlos: EdUFSCar, 2011. O governo do homem endividado. Tradução de Daniel P. P. da Costa. São Paulo: n-1 ediçóes, 2017. 
; NEGRI, Antonio. Trabalho imaterial: formas de vida e produção de subjetividade. Tradução de Mônica Jesus. Rio de Janeiro: DP\&A, 2001.

MATTOS, Pedro Lincoln Carneiro Leão de. Quadro histórico da política de supervisão e controle do governo sobre as universidades Federais autárquicas. Fórum Educacional, v.6, n.3, 1982. Disponível em: http://bibliotecadigital.fgv.br/ojs/index. php/fe/issue/view/3303. Acesso em: 31 mai. 2018.

NEGRI, Antonio. Biocapitalismo. Tradução de Maria Paula Gurgel Ribeiro. São Paulo: Iluminuras, 2015.

OLIVEIRA, Terezinha. Origem e memória das universidades medievais a preservação de uma instituição educacional. Varia hist., v. 23, n. 37, pp. 113-129, 2007.

Disponível em: <http://www.scielo.br/scielo.php?script=sci_arttext\&pid=S010487752007000100007\&lng=pt\&nrm=iso >. Acesso em: 01 out. 2018.

RANIERI, Nina. Autonomia universitária: as universidades públicas e a Constituição Federal de 1988. São Paulo: Editora USP, 1994.

RAPINI, Márcia Siqueira. Interação universidade-empresa no Brasil: evidências do Diretório dos Grupos de Pesquisa do CNPq. Estud. Econ., São Paulo , v. 37, n. 1, p. 211-233, Mar. 2007 . Disponível em: <http://www.scielo.br/scielo.php?script=sci_ arttext\&pid=S0101-41612007000100008\&lng=en\&nrm=iso $>$. Acesso em: 01 out. 2018.

Recebido em 8 out. 2018 / Aprovado em I2 nov. 2018 Para referenciar este texto:

CORRÊA, M. D. C.; CHAVES, J. G. P.; SOUSA, D. P. Governar pela autonomia: universidade, inovação e capitalismo cognitivo. EccoS - Revista Científica, São Paulo, n. 47, p. 81-103. set/dez. 2018. Disponível em: <https://doi.org/10.5585/EccoS. n47.10690>. 
